\title{
A New Method for the Functionalization of [60] Fullerene: An Unusual 1,3-Dipolar Cycloaddition Leading to a $\mathrm{C}_{60}$ Housane Derivative
}

\author{
Zhiguo Zhou and Plato A. Magriotis
}

Department of Chemistry, New York University, 100 Washington Square East, New York, New York 10003

\section{Supporting Information}

MM2 Energy Calculation of $\mathbf{1 a}$ and $\mathbf{1 a}$
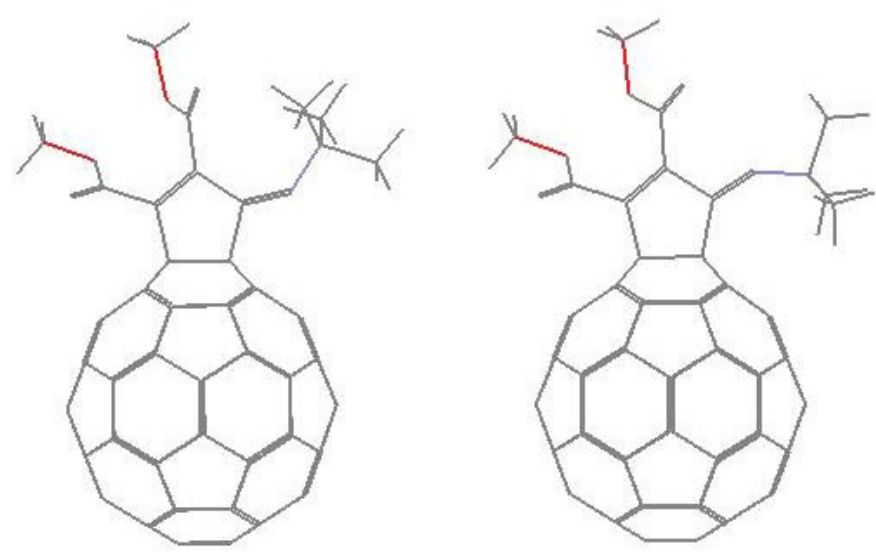

1a-1131.4395 Kcal/mol 1a'-1139.5910 Kcal/mol

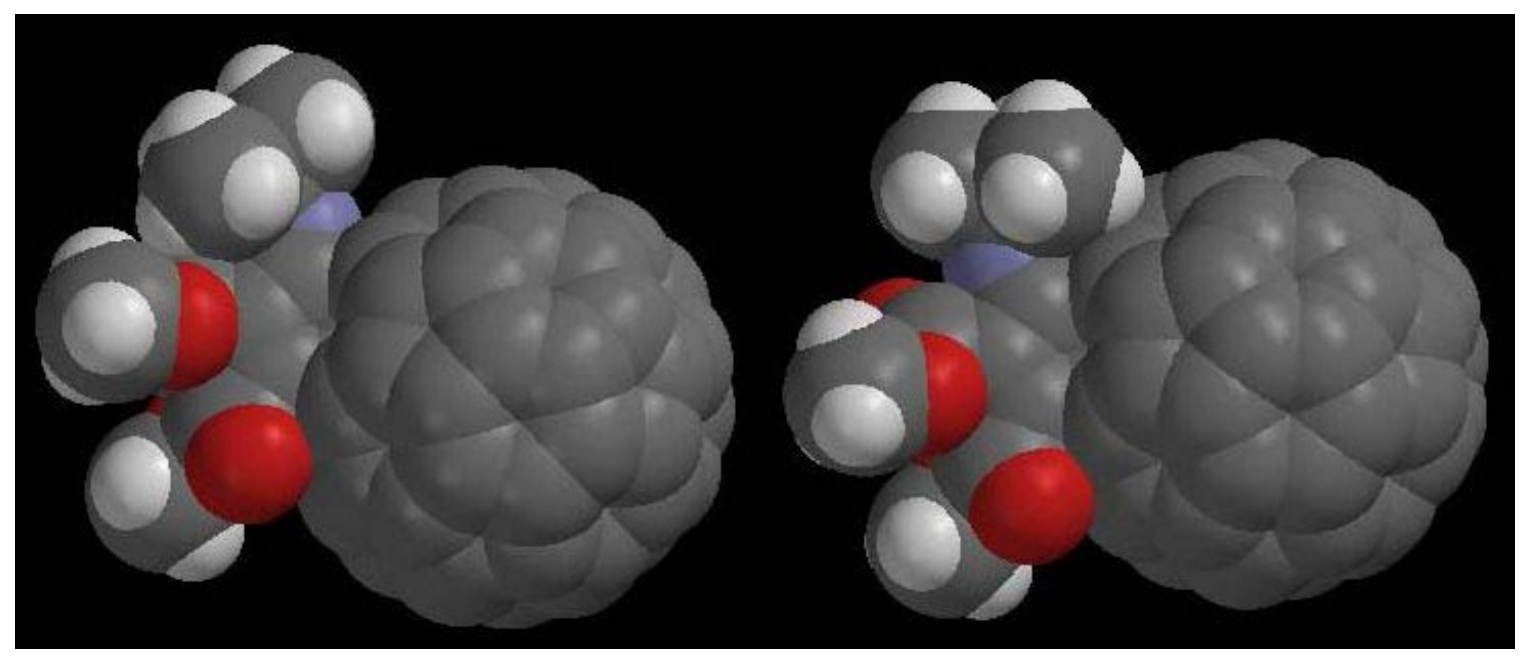


MM2 Energy Calculation of $\mathbf{1 b}$ and $\mathbf{1 b}$,
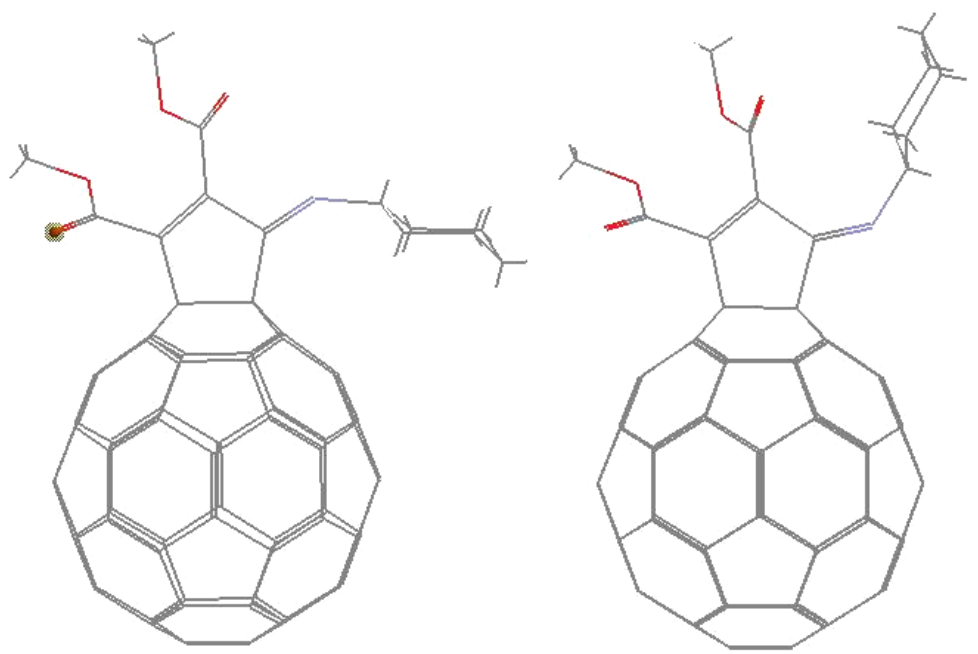

1b'-1133.3543 Kcal/mol

1b-1125.3086 Kcal/mol
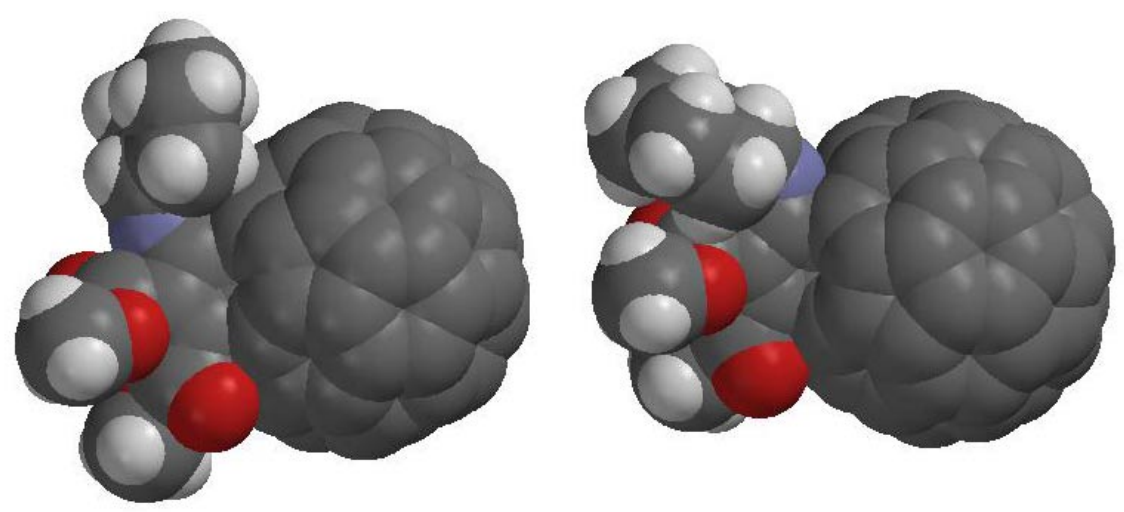